\title{
SOLUÇõES A BASE DE ÁLCOOL PARA HIGIENIZAÇÃo DAS MÃOS E SUPERFÍCIES NA PREVENÇÃO DA COVID-19: COMPÊNDIO INFORMATIVO SOB O PONTO DE VISTA DA QUÍMICA ENVOLVIDA
}

\author{
Rodrigo Sequinel $^{\mathrm{a}, *}$, Guilherme Felipe Lenz ${ }^{\mathrm{a}}$, Francis Josiane Liana Baumgardt da Silva ${ }^{\mathrm{b}}$ e Fabiano Rosa da Silva ${ }^{\mathrm{a}, * *,(1)}$ \\ aDepartamento de Engenharias e Exatas, Universidade Federal do Paraná, 85950-000 Palotina - PR, Brasil \\ bUniversidade Federal do Paraná, 86900-000 Jandaia do Sul - PR, Brasil
}

Recebido em 14/05/2020; aceito em 18/05/2020; publicado na web em 21/05/2020

\begin{abstract}
ALCOHOL BASED SOLUTIONS FOR HAND AND SURFACE SANITATION IN THE PREVENTION OF COVID-19: INFORMATIVE COMPENDIUM REGARDING THE INVOLVED CHEMISTRY. The recent coronavirus pandemic has already victimized hundreds of thousands of people around the world, and until this moment does not exist any medicine for healing or vaccine to avoid the contamination. Therefore, the actions of social isolation associated with the use of masks and surface and hand sanitation are the most effective actions to avoid the virus dissemination. The hands are one of the main vectors of contagious, and should be washed constantly and sanitized with some disinfectant agent. Among the recommendations, the formulations based on ethyl alcohol and isopropyl alcohol are the most used, being the efficiency of these formulations based on the alcohol type, the concentration, the applied volume, and the contact time. The gel disinfectants are preferred by the population due to the facile and safer manipulation. However, due to the pandemic, the main gelling agent has become sparse and, in the function of this, some countries authorized the utilization of alternative formulations. The World Health Organization recommends two formulations, being one based on ethyl alcohol $(80 \mathrm{Vol} \%)$ and the second on isopropyl alcohol (75 Vol\%), destined for the local manufacture and with a fast and effective action.
\end{abstract}

Keywords: coronavirus; COVID-19; SARS-CoV-2; disinfectant, hand sanitizer.

\section{INTRODUÇÃO}

Em março de 2020 a Organização Mundial da Saúde (OMS) caracterizou a doença infecciosa COVID-19 (do inglês Coronavirus Disease 2019) como pandemia, em virtude dos níveis alarmantes de disseminação, severidade e ao estado de inação para o combate. Dos contaminados, estima-se que $80 \%$ apresentem sintomas leves, contudo os $20 \%$ restantes tem uma rápida evolução para inflamações das vias aéreas superiores que levam a insuficiências respiratórias graves, eventual falência dos órgãos e uma parcela significativa a óbito. No Brasil, a taxa de letalidade observada para os pacientes diagnosticados é em torno de 7\%, considerando a estimativa da população brasileira de 211,5 milhões de pessoas, estaríamos vislumbrando a possibilidade de centenas de milhares de óbitos em um curto espaço de tempo, uma tragédia humanitária sem precedentes na história nacional, cujas consequências sanitárias e sociais ainda são imprevisíveis. ${ }^{1,2}$

A hipótese mais aceita até o momento com relação a origem do novo SARS-CoV-2, o sétimo coronavírus a infectar humanos, é que uma cepa do vírus tenha se espalhado a partir de um mercado de frutos do mar na cidade Chinesa de Wuhan, já que o primeiro paciente identificado com a doença visitou o local entre os dias 29 de dezembro de 2019 e 4 de janeiro de 2020, da mesma forma que outras 39 pessoas que também apresentaram a doença. ${ }^{3-6}$ Contudo, sua real origem ainda é desconhecida, como reportado por um estudo recente do Centro de Conservação Integrativa do Jardim Botânico Tropical Xishuangbanna da Academia Chinesa de Ciências. Yu e colaboradores analisaram os dados genéticos de 93 amostras do vírus oriundas de 12 países em 4 continentes, segundo os resultados obtidos neste estudo, o vírus encontrado no mercado em Wuhan teria vindo de algum outro local, cuja real localização ainda segue desconhecida. ${ }^{7-8}$

A COVID-19 se espalha principalmente a partir de microgotas de

*e-mail: rsequinel@gmail.com

**e-mail: frosadasilva@gmail.com saliva ou secreções nasais emitidas quando uma pessoa contaminada tosse ou espirra. $\mathrm{O}$ aerossol contendo o vírus se espalha de forma instantânea no ambiente, atingindo diretamente pessoas e superfícies, onde pode permanecer ativo por alguns dias, dependendo do clima e tipo de material em que foi depositado. Para evitar a exposição direta ao aerossol, recomenda-se o distanciamento social, associado a higienização constante de superfícies e utilização correta de máscaras adequadas. ${ }^{9}$

Em um estudo publicado recentemente na American Chemical Society Nano, Konda e colaboradores compararam a eficiência de 15 tipos de tecidos que poderiam ser utilizados na produção de máscaras faciais caseiras. Os autores verificaram que ao se empregar camadas duplas de algodão com 600 fios por polegada (em geral o algodão comum tem 80 fios por polegada) ou uma camada de algodão com 600 fios juntamente com outra de seda natural, a retenção observada foi similar às máscaras N95 comerciais, porém verifica-se que além do material utilizado é necessário que as máscaras estejam perfeitamente ajustadas à face, sem nenhuma fresta, para impedir a passagem de gotículas por estes locais. Vale destacar que os autores realizaram os testes somente com gotículas de água, uma vez que o vírus pode estar dentro de gotículas quando pessoas contaminadas tossem ou espirram, mas estes não avaliaram a retenção ou passagem de SARS-CoV-2 por estes materiais. ${ }^{10}$

Inevitavelmente, as mãos tornam-se uma das principais vias de contágio ao tocar em superfícies e pessoas contaminadas, devendo ser frequentemente higienizadas para evitar a disseminação do vírus. A higienização por meio da lavagem constante e de maneira correta com água e sabão e/ou a utilização de desinfetantes a base de álcool, principalmente soluções etanólicas ou isopropílicas, são os métodos mais recomendados. ${ }^{11-12} \mathrm{O}$ Quadro 1 apresenta os principais aspectos a serem observados para a escolha entre estes dois métodos.

Os desinfetantes alcoólicos são mais viáveis em locais onde a população não tem fácil acesso à água descontaminada e sabão, como ruas, mercados, locais de trabalho, estações de trens e ônibus 
Quadro 1. Principais aplicações, recomendações e fatores a serem observados na escolha comparativa entre a higienização das mãos com água e sabão ou com soluções alcoólicas

\begin{tabular}{|l|l|}
\hline \multicolumn{1}{|c|}{ Solução alcoólicas } & \multicolumn{1}{|c|}{ Água e sabão } \\
\hline Inativa rapidamente um vasto espectro de patógenos & Recomendado principalmente quando as mãos estão sujas com restos de solo \\
\hline $\begin{array}{l}\text { Útil em locais com ausência de pias e outras facilidades com água descon- } \\
\text { taminada }\end{array}$ & Útil quando as mãos estão contaminadas com materiais proteicos (e.g., sangue) \\
\hline $\begin{array}{l}\text { Em locais de atendimento à saúde, permite a facilidade de distribuição aos } \\
\text { pacientes }\end{array}$ & Opção segura em locais próximos a chamas ou zonas quentes de indústrias \\
\hline $\begin{array}{l}\text { Podem causar menor irritação e sensação de pele seca do que alguns sabões } \\
\text { e detergentes antimicrobianos }\end{array}$ & $\begin{array}{l}\text { Opção em caso de sensibilidade ao uso de soluções a base de álcool etílico } \\
\text { ou isopropílico }\end{array}$ \\
\hline $\begin{array}{l}\text { Contraindicado para pessoas com sensibilidade ou síndrome urticária causada } \\
\text { por álcoois ou componentes da formulação }\end{array}$ & $\begin{array}{l}\text { Recomendado para higienização em casa, por questões de segurança e facili- } \\
\text { dade de manipulação, principalmente para crianças }\end{array}$ \\
\hline $\begin{array}{l}\text { Formulações contendo acima de } 60 \% \text { de álcool são inflamáveis e possuem } \\
\text { baixo ponto de fulgor, podendo saturar o ambiente. Também existe o perigo } \\
\text { de ingestão, necessitando de cuidados adicionais e ações de prevenção }\end{array}$ & $\begin{array}{l}\text { Considerando os materiais necessários, o tempo de lavagem e secagem das } \\
\text { mãos, a higienização com água descontaminada e sabões pode ser mais cara } \\
\text { quando comparada às soluções alcoólicas }\end{array}$ \\
\hline
\end{tabular}

Fonte: WHO, $2009^{11}$ e $2020^{12}$; Huber, et al., 2006. ${ }^{13}$

ou outros espaços de grande circulação populacional. Programas de higienização das mãos são comprovadamente eficientes para diminuir a rápida propagação de infecções do trato respiratório em profissionais da linha de frente de cuidados com a saúde.

Uma pesquisa realizada com 200 profissionais dos Estados Unidos e 150 do Canadá, apontou os principais impedimentos para manter um bom programa de higienização em centros de saúde e hospitais, tendo como base principalmente a utilização de higienizadores a base de álcoois. Segundo este estudo, as principais barreiras que dificultaram a higienização das mãos foram a localização inadequada dos frascos dispensadores, o acúmulo de pessoas para utilização do mesmo frasco, locais com dispensador vazio e o uso de produtos inadequados para a integridade da pele (sensação de pele seca). No entanto, aproximadamente $50 \%$ dos respondentes afirmaram que seriam mais propensos a manter melhores condições de higiene se os frascos estivessem em ambientes mais próximos onde se encontram os pacientes. ${ }^{14}$

\section{Preparações alcoólicas para higienização das mãos (PAHM)}

A utilização de preparações alcoólicas para higienização das mãos é antiga e guarda algumas incertezas em relação a real história dos responsáveis pelas invenções, tendo publicações e patentes relacionadas ao assunto, como também empresas requerendo a exclusividade de explorar a inovação. ${ }^{15,16}$

A eficácia destes produtos vai depender principalmente do tipo de álcool utilizado, da concentração, do volume aplicado e o tempo de contato. ${ }^{11,12,17} \mathrm{Em} 2009$, a Organização Mundial da Saúde publicou um guia extensivo, revisado em abril de 2010, contendo recomendações técnicas a serem adotadas, principalmente em serviços de cuidados com a saúde. ${ }^{11} \mathrm{O}$ guia contém dados científicos relacionados ao tema, informações técnicas de suporte, modelos de transmissão de patógenos, além das principais barreiras e estratégias para a implementação de programas de higienização das mãos. No documento, dentre várias preparações que podem ser utilizadas, a OMS recomenda duas formulações alcoólicas de simples preparação e fácil uso, sendo uma a base de etanol $80 \%$ (v/v) e a outra de isopropanol 75\% (v/v), conforme apresentado no Quadro 2.

Comercialmente, as preparações alcoólicas mais utilizadas podem ser encontradas nas formas líquida, gel ou de espuma, sendo que as formulações podem apresentar variações dependendo do país. ${ }^{18}$ No Brasil, devido a ampla produção de etanol de primeira geração com cana-de-açúcar por processos fermentativos, este se torna mais disponível e economicamente viável para utilização como insumo
Quadro 2. Formulações recomendadas pela Organização Mundial da Saúde, contendo as concentrações finais de cada insumo químico utilizado

\begin{tabular}{|c|c|}
\hline Formulação 1 & Formulação 2 \\
\hline Álcool Etílico a $80 \%(\mathrm{v} / \mathrm{v})$ & Álcool Isopropílico a 75 \% (v/v) \\
\hline Glicerol $1,45 \%(\mathrm{v} / \mathrm{v})^{\mathrm{a}}$ & Glicerol 1,45 \% (v/v) \\
\hline Peróxido de hidrogênio $0,125 \%(\mathrm{v} / \mathrm{v})^{\mathrm{b}}$ & Peróxido de hidrogênio 0,125 \% (v/v) \\
\hline Água destilada, q.s.p. ${ }^{\mathrm{c}}$ & Água destilada, q.s.p. \\
\hline
\end{tabular}

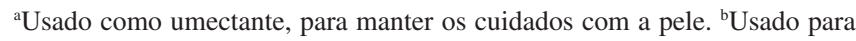
inativar esporos bacterianos contaminantes na solução, não tem como finalidade a ação antisséptica das mãos. 'q.s.p: quantum satis ou "quantidade suficiente" para completar o volume final. Deve estar livre de contaminações. Fonte: WHO, 2009.11

no preparo de soluções, enquanto nos Estados Unidos, por questões culturais e de custo, emprega-se o álcool isopropílico, comercializado naquele país como rubbing alcohol. ${ }^{19,20}$

No Brasil, a Agência Nacional de Vigilância Sanitária (Anvisa) tem publicada a 2a Edição - Revisão 02 de 2012 do Formulário Nacional da Farmacopeia Brasileira, com procedimentos sucintos de produção de formulações higienizantes de álcool etílico $70 \%$ (p/p, equivalente à relação ponderal em massa) e 77\% (v/v), álcool etílico glicerinado $80 \%$ (v/v), álcool isopropílico glicerinado $75 \%$ (v/v) e álcool etílico em gel. ${ }^{21}$

Em território nacional, desde 2002 é recomendada a comercialização de formulações alcoólicas acima de $54^{\circ}$ GL (à temperatura de $20^{\circ} \mathrm{C}$ ) unicamente na forma de gel, por questões de segurança e facilidade de manipulação. Todavia, em virtude da pandemia causada pelo SARS-CoV-2, foi observado um grande desequilíbrio na oferta momentânea de álcool gel, com a demanda por este produto aumentando mais de 10 vezes em relação ao consumo registrado no mesmo período de 2019. Desta maneira, o Brasil e outros países autorizaram, em caráter excepcional, por meio de suas agências oficiais de vigilância sanitária ou órgão correspondente, a fabricação de formulações alternativas, sendo uma dessas a forma líquida recomendada pela OMS. ${ }^{19,22,23}$

Nesta linha, em 24/03/2020 a Anvisa publicou um guia intitulado "Orientações Gerais para a Produção de Formulações Antissépticas", com base no guia da OMS de 2009 (revisão de 2010) e na $2^{\text {a }}$ edição do Formulário Nacional da Farmacopeia Brasileira de 2012. ${ }^{22} \mathrm{O}$ material contém instruções de fabricação e cita a RDC 350/2020 da Anvisa, que define os critérios temporários para fabricação e comercialização de preparações antissépticas sem prévia autorização 
da agência. Empresas e farmácias magistrais foram favorecidas, em vista da urgência, com a possibilidade de incorporar a atividade de produção de soluções alcoólicas, sem a necessidade de autorização específica para o produto, desde que já possuíssem autorização de funcionamento e licença sanitária vigentes. ${ }^{11,21,22}$

\section{Soluções líquidas}

Uma solução é uma mistura homogênea de duas ou mais substâncias na mesma fase, com o componente em maior quantidade sendo definido como solvente e o outro como soluto, não estando, portanto, esta definição atrelada exclusivamente ao estado físico dos participantes. As soluções líquidas têm como solventes espécies no estado líquido, podendo apresentar gases, líquidos ou sólidos dissolvidos. Quando um soluto é dissolvido em um líquido, algumas de suas propriedades coligativas são alteradas, tais como os pontos de ebulição, de congelamento, pressão osmótica e pressão de vapor. Estas alterações ocorrem pelo fato destas propriedades dependerem do número relativo de partículas de soluto por molécula de solvente. ${ }^{20,24}$

Água e etanol são miscíveis em todas as proporções, com a energia de formação deste sistema sendo favorecida pelo estabelecimento de efetivas forças intermoleculares do tipo ligação de hidrogênio entre os grupos -OH de ambas as moléculas. Porém, o principal fator que impulsiona o processo de dissolução destas substâncias é o aumento da entropia do sistema, uma vez que o desordenamento originado na solução é maior do que aquele observado quando as moléculas estão separadas. ${ }^{20}$

\section{Soluções em gel}

Por volta de 1860, o conceito de coloides, também denominados dispersões coloidais, foi apresentado por Thomas Graham. Estas substâncias foram definidas como misturas de dois ou mais compostos que apresentam propriedades intermediárias entre soluções e suspensões. Inicialmente estas definições tinham como principal característica a dificuldade de cristalização, porém nenhuma linha divisória definitiva pode ser estabelecida somente com base nesta propriedade. De maneira mais abrangente, os coloides podem ser definidos levando em consideração outras duas características. A primeira é que estes compostos possuem massas molares elevadas, e a segunda é que as partículas coloidais são relativamente grandes ( 1000 nm de diâmetro), o que possibilita que estes compostos apresentem um fenômeno ótico de dispersão da luz visível (efeito Tyndall). ${ }^{20,24}$

Dentro da conceituação dos coloides, também podem ser descritos os sóis e os géis. Um sol é uma dispersão de uma substância sólida em um meio fluido. Já um gel é uma rede coloidal não fluida ou uma rede polimérica expandida em todo o seu volume por um fluido. Por exemplo, a gelatina é um sol quando o pó de preparo é misturado com água fervendo, mas torna-se um gel quando refrigerada; ou ainda, precipitados gelatinosos dos hidróxidos de $\mathrm{Al}^{+3}, \mathrm{Fe}^{+3}, \mathrm{Cu}^{+2}$ e o álcool em gel utilizado na assepsia das mãos e superfícies..$^{20,25}$

\section{Álcool em gel}

O álcool em gel (gel alcoólico) é uma das formas mais rápidas e utilizadas para higienização das mãos e superfícies. As formulações deste composto geralmente utilizam para sua elaboração etanol $96 \%$ (v/v), solução de trietanolamina a $5 \%$ (p/v) como neutralizante, glicerol como umectante, água purificada e um gelificante. O gelificante tem como função a alteração da reologia da mistura e sua estabilização. Estes compostos possuem em suas estruturas grupamentos -OH ou - $\mathrm{COOH}$, tais como a carboximetil celulose (CMC) ou um carbômero hidrossolúvel como o carbopol (Figura 1). (a)

(b)
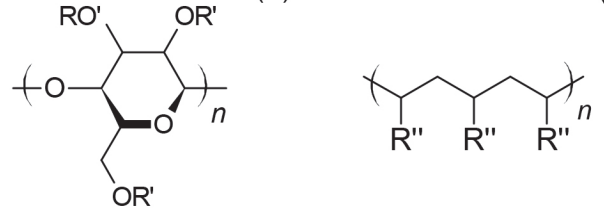

$$
\mathrm{R}^{\prime}=-\mathrm{H} \text { ou }-\mathrm{CH}_{2} \mathrm{CO}_{2} \mathrm{H} \quad \mathrm{R}^{\prime \prime}=-\mathrm{COOH}
$$

Figura 1. Estruturas da carboximetil celulose (a) e do carbopol (b)

Estes compostos estabelecem fortes interações intermoleculares do tipo ligação de hidrogênio com as moléculas de etanol, glicerol e água, gerando estabilização do gel. ${ }^{21,26,27}$ Por questões de disponibilidade e preço, o gelificante mais utilizado para formulações de álcool em gel é um carbômero conhecido comercialmente como carbopol, descrito no Formulário Nacional da Farmacopeia Brasileira como carbômer $980 .^{21,27}$

Os primeiros carbômeros comerciais, como o carbopol, foram criados há mais de 50 anos e são polímeros do ácido poliacrílico, geralmente reticulados com alil-sacarose ou alil-pentaeritritol, contendo entre 56 e $68 \%(\mathrm{~m} / \mathrm{m})$ de grupos ácido carboxílico, e alto peso molecular entre $7 \times 10^{5}$ a $4 \times 10^{9} \mathrm{Da}$. As propriedades destes polímeros podem ser ajustadas com base no tipo de solvente utilizado na polimerização (benzeno, acetato de etila ou uma mistura de acetato de etila e ciclo-hexano) e no tipo de monômero, sendo possível a obtenção de homopolímeros (apenas um tipo de unidade de repetição), copolímeros (uma mistura de unidades repetitivas) ou interpolímeros. ${ }^{28,29}$

Devido a escassez e consequente aumento de custo do carbopol, pelo aumento da demanda em virtude da pandemia, alternativas estão sendo desenvolvidas para a sua substituição. No Paraná, uma equipe de pesquisadores do Laboratório da Tecnologia da Madeira da Empresa Brasileira de Pesquisa Agropecuária (Embrapa) Florestas, em parceria com a empresa Klabin (parque de plantas piloto localizado em Telêmaco Borba-PR), produziu álcool 71,83\% (m/m) desinfetante, utilizando como agente gelificante nanocelulose microfibrilada obtida do branqueamento de pinus e eucalipto. ${ }^{27}$

\section{Álcool etílico glicerinado conforme formulação da OMS}

Conforme mencionado acima, a Anvisa flexibilizou recentemente a fabricação e distribuição em todo território nacional, da formulação de álcool etílico glicerinado $80 \%$ (v/v) preconizado pela OMS. Porém, assim como qualquer outra formulação química, recomenda-se seguir os seguintes cuidados na sua preparação:

- Verificar as orientações contidas no Guia de Produção Local da Organização Mundial de Saúde, disponível em: https://www.who. int/gpsc/5may/Guide_to_Local_Production.pdf ${ }^{11}$

- Produzir em local seguro, com estrutura apropriada e sob a responsabilidade de profissionais capacitados;

- Utilizar equipamentos e utensílios devidamente higienizados;

- Realizar testes de qualidade nos insumos empregados na preparação;

- Realizar testes de qualidade no produto final (e.g., teor alcoólico, pH e análise de qualidade microbiológica);

- Envasar o produto em frascos adequados;

- Rotular com todas as informações necessárias, de forma clara e de fácil entendimento;

- Todo produto formulado deve permanecer em quarentena de $72 \mathrm{~h}$ antes de ser utilizado ou distribuído. Isso permite que o peróxido de hidrogênio contido na formulação possa eliminar agentes infecciosos presentes no álcool ou nos recipientes de envase;

- Distribuir os produtos para terceiros somente mediante orientação e autorização prévia de órgãos legais competentes. . $^{30,31}$ 


\section{Determinação do teor alcoólico com base na formulação de etanol $80 \%(\mathrm{v} / \mathrm{v})$ da OMS}

As preparações alcoólicas para higienização das mãos podem apresentar o teor de álcool variando entre 60 a $95 \%$ a depender do tipo de insumo utilizado e da unidade de medida em que a concentração final é reportada. ${ }^{11} \mathrm{O}$ teor final do princípio ativo pode ser informado em fração de volume, álcool por volume (ABV - alcohol by volume) ou conteúdo em massa, álcool por massa (ABW - alcohol by weight) que é equivalente ao ${ }^{\circ} \mathrm{INPM}$, expressão usada somente em território brasileiro, conforme normatizado pelo Instituto Nacional de Pesos e Medidas..$^{27,32}$

Em um breve contexto histórico, o embasamento para a determinação do teor alcoólico de misturas de álcool e água foi proposto entre os séculos XVII e XVIII, principalmente na Inglaterra, devido ao intenso comércio de bebidas. O governo britânico propôs taxas mais rígidas para diferentes bebidas com base no teor de etanol. Foi necessário aprimorar o sistema de medição, visto que até então os valores eram grosseiramente avaliados a partir da queima direta das bebidas em combinação com materiais explosivos. Ao final da queima da mistura, caso fosse observada uma pequena explosão, a bebida era classificada como "acima da prova" (over proof, relacionado a um teor alcoólico mais elevado), caso fosse observado o contrário, ausência de explosão no final da queima, a bebida era classificada como "abaixo da prova" (under proof). . $^{33-35}$

A partir das contribuições de Robert Boyle, John Clarke, Bartholomew Sikes, da Royal Society e outros pesquisadores, foi desenvolvido o hidrômetro de precisão. Ao longo do desenvolvimento, foram realizados vários testes para determinar a densidade relativa aparente de misturas de etanol e água, tendo como referência a temperatura de $60{ }^{\circ} \mathrm{F}\left(15,56^{\circ} \mathrm{C}\right)$. A partir das diferenças existentes nas densidades relativas do etanol e água puros, era possível determinar a densidade relativa das misturas e estabelecer uma relação direta para chegar ao teor etílico das bebidas. ${ }^{34}$

Na França, em 1824, Joseph Louis Gay-Lussac deu sua contribuição com o aprimoramento do alcoômetro centesimal volumétrico, no qual o zero representava a água sem álcool e o máximo da escala somente álcool puro. Suas medições foram realizadas a $15^{\circ} \mathrm{C}(59$ $\left.{ }^{\circ} \mathrm{F}\right)$ e, neste caso, um resultado de $80^{\circ} \mathrm{GL}$, correspondia a presença de 80 frações em volume de etanol a cada 100 frações em volume da mistura total, a $15{ }^{\circ} \mathrm{C} .33,35$

Em ambos os sistemas inglês ou francês ainda vigentes, bem como nos demais que surgiram em outros países, as medidas realizadas em frações de volume (ABV), devem passar pela correção do teor alcoólico em função da temperatura, com auxílio de tabelas de conversão, visto que a densidade de um líquido varia significativamente com a temperatura. Devido à existência de vários sistemas, a partir de 1966 a Seção de Industrias de Fermentação da União Internacional de Química Pura e Aplicada (IUPAC), propôs a adoção de uma forma padronizada de modo que as medições pudessem ser comparadas a $20{ }^{\circ} \mathrm{C}$. Entre os vários métodos oficiais de medida, foram todos inicialmente desenvolvidos, à época, sob regulações e padrões vigentes em cada um dos países, como por exemplo, os diferentes padrões de temperatura adotados. O documento da IUPAC traz menção sobre a dificuldade em se realizar a purificação do etanol absoluto visando obter um valor exato para a concentração alvo de $100 \%$ de etanol, livre de quaisquer impurezas que pudessem causar desvios nas medidas. Além disso, foi mencionado as diferentes abordagens em relação ao uso dos termos densidade e densidade relativa (na época denominada gravidade específica).36 Tais diferenças contribuem para as pequenas variações encontradas na Tabela para os métodos realizados à mesma temperatura.

Na Tabela 1 são apresentadas algumas conversões do teor alcoólico de massa ponderal (\% massa) para porcentagem em volume utilizando diferentes métodos oficiais de medição.36,37 Os valores de teor alcoólico em massa independem da temperatura.

No caso da formulação da OMS, o guia para produção local traz em seu roteiro a preparação de $10 \mathrm{~L}$ de solução de álcool etílico glicerinado $80 \%(\mathrm{v} / \mathrm{v})$ a partir de etanol concentrado a $96 \%(\mathrm{v} / \mathrm{v})$. Para preparar diferentes volumes de higienizador, a partir desta ou outras soluções de etanol concentrado, pode ser utilizada a Equação 1:

$$
Y=\frac{V \times b}{a}
$$

onde: $\mathrm{Y}$ = volume de etanol a ser tomado para preparação; $\mathrm{V}=$ volume final da solução de etanol glicerinado $80 \%$ (v/v) que se pretende preparar; $b=$ concentração final da solução de etanol glicerinado $80 \%$ (v/v), na temperatura de referência; $a=$ concentração de etanol em fração volumétrica, na temperatura de referência.

Desta forma, partindo do etanol concentrado em $96 \%$ (v/v), são necessários 8,333 L para obtenção de $10 \mathrm{~L}$ de formulação $80 \%$. Após a preparação, o teor alcoólico deve ser conferido com auxílio de um alcoômetro volumétrico centesimal, sendo que os limites aceitos para a formulação final podem ficar no intervalo entre 75 e $85 \%(\mathrm{v} / \mathrm{v}){ }^{22}$

Em etapa prévia à preparação, convém testar o conteúdo de etanol no álcool concentrado, também com auxílio de um alcoômetro volumétrico centesimal conforme mostra a Figura 2, sendo que as temperaturas de medição devem ser anotadas e posteriormente corrigidas para os valores de referência. Por exemplo, o Formulário Nacional da Farmacopeia Brasileira traz em seu Anexo B uma tabela de conversão dos valores de teor alcoólico para a temperatura de $15^{\circ} \mathrm{C}$. No caso da IUPAC, deve se utilizar a temperatura de referência de $20^{\circ} \mathrm{C}^{21,37}$

O resultado de teor de etanol no produto álcool etílico glicerinado, cujo teor alvo é $80 \%$ (v/v), pode ser convertido em título ponderal, ou percentual de etanol absoluto em massa (ABW), também denominado

Tabela 1. Conversão do teor alcoólico (ABW) para (ABV) e comparação de alguns valores entre os principais métodos de medição vigentes em diferentes países

\begin{tabular}{|c|c|c|c|c|c|c|}
\hline$\%$ massa & $\begin{array}{c}\% \text { volume } 20^{\circ} \mathrm{C} \\
\text { IUPAC }\end{array}$ & $\begin{array}{c}\% \text { volume } 15,56{ }^{\circ} \mathrm{C} \\
\text { U.S Bur. }\end{array}$ & $\begin{array}{c}\% \text { volume } 15^{\circ} \mathrm{C} \\
\text { Osborne }\end{array}$ & $\begin{array}{c}\% \text { volume } 15^{\circ} \mathrm{C} \\
\text { Gay-Lussac }\end{array}$ & $\begin{array}{c}\% \text { volume } 15,56{ }^{\circ} \mathrm{C} \\
\text { Inglês }\end{array}$ & $\begin{array}{c}\% \text { volume } 20^{\circ} \mathrm{C} \\
\text { Norueguês }\end{array}$ \\
\hline 1 & 1,26 & 1,26 & 1,26 & 1,21 & 1,26 & 1,26 \\
\hline 10 & 12,44 & 12,39 & 12,39 & 12,31 & 12,43 & 12,44 \\
\hline 20 & 24,54 & 24,47 & 24,46 & 24,32 & 24,54 & 24,54 \\
\hline 50 & 57,89 & 57,83 & 57,82 & 57,66 & 57,87 & 57,89 \\
\hline 70 & 76,95 & 76,91 & 76,90 & 76,89 & 76,91 & 76,94 \\
\hline 80 & 85,48 & 85,46 & 85,46 & 85,44 & 85,49 & 85,48 \\
\hline
\end{tabular}

Fonte: IUPAC (1968), adaptado. ${ }^{37}$ 

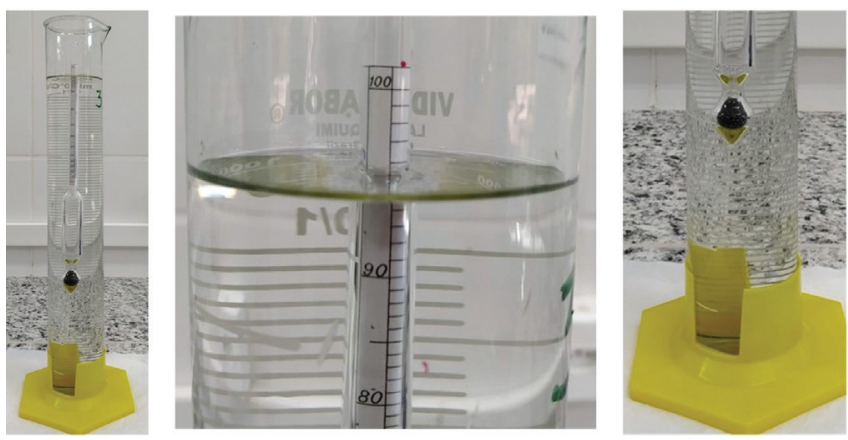

Figura 2. Verificação do teor alcoólico em etanol $96 \%(v / v)$ utilizando alcoômetro de vidro. O ponto de leitura é na parte inferior do menisco

${ }^{\circ}$ INPM que representa a quantidade em gramas de álcool etílico contida em 100 gramas de uma mistura hidro-alcooólica. Neste caso, deve-se considerar a Equação 2:37

$$
I N P M=\frac{A B V \times M e}{M m}
$$

onde: $\mathrm{INPM}=$ teor de etanol em $\% \mathrm{~m} / \mathrm{m}(\mathrm{ABW}) ; \mathrm{ABV}=$ teor de etanol em \% volume; $\mathrm{Me}=$ densidade do etanol absoluto (puro) na temperatura de referência; $\mathrm{Mm}=$ densidade da mistura etanol/água na temperatura de referência.

Tomando como base o Anexo A do Formulário Nacional da Farmacopeia Brasileira, a densidade do etanol absoluto é 0,79433 a $15{ }^{\circ} \mathrm{C}$. Por sua vez, nesta mesma tabela, a mistura etanol/água 80 $\%$ (v/v) apresenta densidade de 0,86416 , o que resulta em um título ponderal de $73,53 \%(\mathrm{~m} / \mathrm{m})$. Em tabelas alcoométricas, tal qual a descrita no formulário da farmacopeia brasileira, é comum se utilizar uma medida adimensional para densidade, a qual consiste na razão entre as massas de um volume conhecido da mistura hidro-alcoólica e a massa de um mesmo volume de água numa mesma temperatura. ${ }^{21}$

É importante ressaltar que a medida real do teor de etanol tendo como base determinações a partir de leituras em hidrômetros ou alcoômetros, só podem ser realizadas com exatidão em misturas únicas de água/etanol em temperaturas conhecidas. A presença de outras substâncias dissolvidas, tais como peróxido de hidrogênio e glicerol, mesmo como componentes minoritários, como é o caso da formulação da OMS, proporcionam pequenos desvios na densidade da mistura, tendo como consequência desvios no teor de etanol na formulação final. Todavia, os valores permanecem dentro da faixa de variação recomendada pela OMS entre 75 a $85 \%$ (v/v). Para determinação exata do teor de etanol nestes casos, há necessidade da utilização de processos físicos de destilação (com aplicação de fatores de correção nas fórmulas acima) e/ou métodos mais sofisticados de análise, como a cromatografia líquida de alta eficiência ou a cromatografia gasosa. ${ }^{38}$

\section{CONCLUSÃO}

Os primeiros casos de COVID-19 foram reportados na China no final de 2019 e já vitimaram centenas de milhares de pessoas em todo o mundo. Estima-se que atualmente ao menos 2,8 bilhões de pessoas estejam vivendo sob algum tipo de distanciamento social para contenção da contaminação, uma vez que ainda não temos medicamento para a cura e nem vacina para evitar a contaminação. O distanciamento social associado a utilização de máscaras e higienização das superfícies e das mãos com água e sabão e/ou agentes desinfetantes, são até o momento os métodos mais efetivos para evitar o aumento das internações em um curto espaço de tempo e impedir o colapso dos sistemas de saúde e agravamento da crise.
Dentre os desinfetantes disponíveis, o etanol em gel é o mais utilizado pela acessibilidade e segurança de manipulação, porém este se tornou escasso devido à grande demanda em virtude da pandemia que estamos atravessando, gerando falta dos principais gelificantes comumente utilizados. Os antissépticos líquidos têm sido uma ótima opção para suprir a escassez de álcool em gel, com a OMS recomendando a produção de formulações a base de etanol $80 \%$ (v/v) ou de isopropanol $75 \%$ (v/v) glicerinados e muitas agências reguladoras flexibilizando as normas de fabricação e distribuição de formulações antissépticas alcoólicas. Todavia, estas soluções devem ser preparadas por profissionais qualificados, em locais apropriados e seguindo os protocolos estabelecidos, com sua distribuição devendo respeitar as orientações vigentes dos órgãos técnicos responsáveis.

\section{AGRADECIMENTOS}

Este artigo foi idealizado durante a Força-Tarefa Voluntária para produção de solução de álcool etílico glicerinado na UFPR, Setor Palotina. Os autores agradecem a UFPR e a comunidade universitária por proporcionarem a estrutura e apoio necessários. Agradecem a parceira da comunidade palotinense, empresas e empresários que se juntaram à causa, por meio de doações de materiais e recursos, para viabilizar a produção e distribuição do higienizador. Até o momento, parte da produção vem sendo utilizada pelos servidores na própria UFPR e a maior parte é distribuída gratuitamente a entidades públicas e ações sociais da cidade de Palotina-PR.

\section{REFERÊNCIAS E NOTA}

1. https://www.saude.gov.br/noticias/agencia-saude/46825-brasil-registra101-147-casos-de-coronavirus-e-7-025-mortes-pela-doenca, acessada em Maio 2020.

2. https://www.ibge.gov.br/, acessada em Março 2020.

3. https://www.dw.com/pt-br/not\%C3\%ADcias/s-7111, acessada em Março 2020.

4. Andersen, K. G.; Rambaut, A.; Lipkin, W. I.; Holmes, E. C.; Garry, R. F.; Nat. Med. 2020, 26, 450 .

5. http://www.china.org.cn/china/2020-02/23/content_75735781.htm, acessada em Março 2020.

6. Chan, J. F-W.; Yuan S.; Kok, K-H.; To, K. K-W.; Chu, H.; Yang, J.; Xing, F.; Liu, J.; Yip, C. C-Y.; Poon, R. W-S.; Tsoi, H-W.; Lo, S. K-F.; Chan, K-H.; Poon, V. K-M.; Chan, W-M.; Ip, J. D.; Cai, J-P.; Cheng, V. C-C.; Chen, H.; Hui, C. K-M.; Yuen, K-Y.; Lancet 2020, 395, 514.

7. http://www.chinaxiv.org/abs/202002.00033, acessada em Março 2020.

8. http://english.cas.cn/, acessada em Março 2020.

9. Kampf, G.; Todt, D.; Pfaender, S.; Steinmann, E.; J. Hosp Infect. 2020, 104, 246.

10. Konda, A.; Prakash, A.; Moss, G. A. Schmoldt, M.; Grant, G. D.; Guha S.; ACS Nano (2020), doi: https://dx.doi.org/10.1021/acsnano.0c03252.

11. https://www.who.int/gpsc/5may/tools/9789241597906/en/, acessada em Março 2020.

12. https://www.who.int/publications-detail/water-sanitation-hygiene-andwaste-management-for-covid-19, acessada em Março 2020.

13. Huber, M. A.; Holton, R. H.; Terezhalmy, G. T.; J. Contemp. Dent. Pract. 2006, 2, 1 .

14. Kirk, J.; Kendal, A.; Marx, J. F.; Pincock, T.; Young, E.; Hughes, J. M.; Landers, T.; Am. J. Infect. Control 2016, 44, 1095.

15. https://www.theguardian.com/society/2012/may/13/do-we-really-needhand-sanitisers, acessada em Maio 2020.

16. https://invention.si.edu/lupe-hernandez-and-invention-hand-sanitizer, acessada em Maio 2020.

17. Zingg, W.; Haidegger, T.; Pittet, D.; Am. J. Infect. Control 2016, 44, 1689. 
18. Greenaway, R. E.; Ormandy, K.; Fellows, C.; Hollowood, T.; J. Hosp. Inf. 2018, 100, 195.

19. https://www.fda.gov/media/136118/download, acessada em Abril 2020.

20. Kotz, J. C.; Treichel, P. M.; Weaver, G. C.; Química Geral e Reações Químicas, 6.ed., Cengage Learning: São Paulo, 2014.

21. Ministério da Saúde. Agência Nacional de Vigilância Sanitária; Formulário nacional da farmacopeia brasileira, 2.ed., Brasília: Anvisa, 2012.

22. http://portal.anvisa.gov.br/documents/219201/4340788/Orienta\%C3\%A 7\%C3\%B5es+para+produzir+\%C3\%A1lcool+gel/32afa23c-8d7b-46159f74-d1dc407b1aa3, acessada em Março 2020.

23. https://www.canada.ca/en/health-canada/services/drugs-health-products/ drug-products/applications-submissions/guidance-documents/covid-19expediated-licensing-alcohol-hand-sanitizer.html, acessada em Maio 2020.

24. Atkins, P.; Jones, L.; Princípios de Química: Questionando a Vida Moderna e o Meio Ambiente, 3.ed., Bookman: Porto Alegre, 2006.

25. International Union of Pure and Applied Chemistry.; Compendium of Chemical Terminology Gold Book, Version 2.3.3., IUPAC: Zurique, 2014.

26. Fujimoto, J.; Reis, E. A. O.; Petri, D. F. S.; Quim. Nova 2002, 25, 757.

27. Magalhães, W. L. E.; Degenhardt, J.; Com. Tec. 2020, 444, 1.

28. Kulkarni, V. S.; Shaw, C.; Essential Chemistry for Formulators of Semisolid and Liquid Dosages, Elservier: San Diego, 2016.

29. https://www.lubrizol.com/Health/Pharmaceuticals/Excipients/CarbopolPolymer-Products, acessada em Março 2020.

30. https://www.ufpr.br/portalufpr/noticias/setor-palotina-disponibilizaorientacoes-para-producao-de-alcool-80-com-formula-da-oms/, acessada em Março 2020.
31. http://cfq.org.br/noticia/nota-oficial-esclarecimentos-sobre-alcool-gelcaseiro-higienizacao-de-eletronicos-e-outros/, acessada em Março 2020.

32. http://www.agencia.cnptia.embrapa.br/Repositorio/Especificacoes_doAlcool_Focado_para_Mercado_Mundial_000fxgfcrtu02wyiv80soht $9 \mathrm{~h}$ al6t8qx.pdf, acessada em Abril 2020.

33. Klein, H. A.; The Science of Measurement: A Historical Survey. Dover Publications INC: New York, 1988.

34. Ashworth, W. J.; Technol. Cult. 2001, 42, 27.

35. Jensen, W. B.; J. Chem. Edu. 2004, 81, 1258.

36. Entre os vários métodos oficiais de medida, foram todos inicialmente desenvolvidos, à época, sob regulações e padrões vigentes em cada um dos países, como por exemplo, os diferentes padrões de temperatura observados na Tabela. O documento da IUPAC traz menção sobre a dificuldade em se realizar a purificação do etanol absoluto visando obter a concentração alvo de $100 \%$ de etanol, livre de quantidades significativas de água e outras impurezas que pudesse causar desvios nas medidas. Além disso, foi mencionado as diferentes abordagens em relação ao uso dos termos densidade e densidade relativa (na época denominada gravidade específica) entre os métodos. Tais diferenças em geral contribuem para as pequenas variações encontradas na Tabela para mesma unidade de medida na mesma temperatura.

37. International Union of Pure and Applied Chemistry.; A Standardization of Methods for Determination of the Alcohol Content of Beverages and Distilled Potable Spirits, IUAPC: London, 1968.

38. https://www.canada.ca/en/revenue-agency/services/tax/technicalinformation/excise-act-2001-technical-information/canadianalcoholometric-obscuration-equivalent-tables-1993.html, acessada em Abril 2020 